\title{
Independent Risk Factors for Hepatocellular Carcinoma Recurrence after Direct-Acting Antiviral Therapy in Patients with Chronic Hepatitis C
}

\author{
Young-Hwan Ahn', Heirim Lee ${ }^{2,3}$, Do Young Kim', Hye Won Lee ${ }^{4}$, Su Jong Yư ${ }^{5}$, Young Youn Cho ${ }^{5,6}$, Jeong Won \\ Jang $^{7}$, Byoung Kuk Jang ${ }^{8}$, Chang Wook Kim ${ }^{9}$, Hee Yeon Kim ${ }^{9}$, Hana Park ${ }^{10}$, Hyo Jung Cho ${ }^{1}$, Bumhee Park ${ }^{2,3}$, \\ Soon Sun Kim¹, and Jae Youn Cheong ${ }^{1}$ \\ Departments of ${ }^{1}$ Gastroenterology, ${ }^{2}$ Biomedical Informatics, and ${ }^{3}$ Office of Biostatistics, Ajou Research Institute for Innovative \\ Medicine, Ajou University School of Medicine, Suwon, ${ }^{4}$ Department of Internal Medicine, Yonsei University College of Medicine, \\ ${ }^{5}$ Department of Internal Medicine and Liver Research Institute, Seoul National University College of Medicine, ${ }^{6}$ Department of Internal \\ Medicine, Chung-Ang University Hospital, ' Department of Internal Medicine, College of Medicine, The Catholic University of Korea, \\ Seoul, ${ }^{8}$ Department of Internal Medicine, Keimyung University School of Medicine, Daegu, ${ }^{9}$ Division of Hepatology, Department of \\ Internal Medicine, Uijeongbu St. Mary's Hospital, College of Medicine, The Catholic University of Korea, Seoul, and ${ }^{10}$ Department of \\ Internal Medicine, CHA Bundang Medical Center, CHA University, Seongnam, Korea
}

See editorial on page 327.

\section{Article Info}

Received May 12, 2020

Revised June 12, 2020

Accepted June 15, 2020

Published online September 9, 2020

\section{Corresponding Author}

Jae Youn Cheong

ORCID https://orcid.org/0000-0001-6246-1783

E-mail jaeyoun620@gmail.com

\section{Soon Sun Kim}

ORCID https://orcid.org/0000-0002-6862-1896

E-mail cocorico99@gmail.com

Young-Hwan Ahn and Heirim Lee contributed equally to this work as first authors.
Background/Aims: This study was performed to evaluate the efficacy of direct-acting antivirals (DAAs) in Korean patients with hepatitis $\mathrm{C}$ virus (HCV)-related hepatocellular carcinoma (HCC) and to investigate the risk factors associated with $\mathrm{HCC}$ recurrence.

Methods: A total of 100 patients with HCV-related HCC, who were treated with DAAs between May 2015 and December 2016, were recruited from seven university hospitals in Korea. Claim data of 526 patients with HCC obtained from the Health Insurance Review and Assessment Service in South Korea were used for external validation of the results.

Results: Among the 100 patients, $88 \%$ achieved a sustained virological response (SVR) 12 weeks after the end of DAA therapy (SVR12), and 37\% experienced HCC recurrence after DAA therapy. Short last HCC treatment durability ( $<12$ months) before DAA commencement was independently associated with $\mathrm{HCC}$ recurrence (hazard ratio [HR], 2.89; $\mathrm{p}=0.011$ ). In the nationwide validation cohort, $20.3 \%$ of the patients experienced HCC recurrence. The last HCC treatment with a noncurative method, a short last HCC treatment durability ( $<12$ months), and a longer total duration of HCC treatment ( $\geq 18$ months) were independently related with $\mathrm{HCC}$ recurrence (HR 3.73, $p<0.001$; HR 3.34, $p<0.001$; and HR 1.74, $p=0.006$; respectively).

Conclusions: DAA therapy showed an acceptable SVR12 rate in patients with HCV-related HCC. Short last HCC treatment durability ( $<12$ months) was associated with HCC recurrence after DAA therapy. This finding suggests that the last HCC treatment durability is an important predictor of HCC recurrence after DAA therapy. (Gut Liver 2021;15:410-419)

Key Words: Carcinoma, hepatocellular; Antiviral agents; Risk factors; Hepatitis C, chronic; Recurrence

\section{INTRODUCTION}

Chronic infection with hepatitis $\mathrm{C}$ virus ( $\mathrm{HCV}$ ) is a well-known risk factor for liver cirrhosis and hepatocellular carcinoma (HCC), which is one of the most common and fatal malignancies globally. ${ }^{1,2}$ Direct-acting antivirals
(DAAs) exhibit an excellent efficacy against $\mathrm{HCV}^{3-6}$ While the pegylated interferon plus ribavirin therapy approved in 2001 shows a sustained virological response (SVR) of $42 \%$ to $46 \%$ in genotype 1 and $76 \%$ to $82 \%$ in genotypes 2 or $3,{ }^{7,8}$ the success rate of DAA therapy is over $86 \%$, even in patients with a decompensated or an advanced liver 
disease. ${ }^{9,10}$ Consequently, DAAs have become an indispensable element of hepatitis $C$ treatment. Recently, the World Health Organization has set a goal to treat $80 \%$ of the global hepatitis $\mathrm{C}$ cases, and reduce annual deaths due to viral hepatitis by $35 \%$, by $2030 .{ }^{11}$ It is important to elucidate reasonable study outcomes to reduce the uncertainty surrounding DAA therapy, and to allow more patients to be treated, including patients with HCV-associated HCC.

Reportedly, patients with HCC are more resistant to DAA therapy than those without HCC. ${ }^{12-14}$ SVR rates of $74.4 \%$ to $79 \%$ and $88 \%$ to $91.1 \%$ were recorded in American patients with and without HCC, respectively. ${ }^{13,14}$ However, little is known about the efficacy of DAA therapy in the Asian population. Recent studies have reported unexpectedly high rates of HCC recurrence after a successful DAA treatment. ${ }^{15-17}$ While a meta-analysis showed no difference in HCC recurrence following DAA or interferon therapy after adjusting for study follow-up time and patient age, ${ }^{18}$ the issue raises an uncertainty about the appropriate timing of treatment of HCV-infected patients with a history of HCC. Therefore, it is important to identify risk factors associated with HCC recurrence in the DAA-treated patients.

The aim of this study was to evaluate the therapeutic efficacy of DAAs in Asian patients with a history of HCVinduced HCC, and investigate the risk factors for HCC recurrence after DAA therapy.

\section{MATERIALS AND METHODS}

\section{Patient selection}

We retrospectively recruited 100 patients with HCVinfected HCC from seven university hospitals in South Korea. Patients who achieved complete response (CR) after HCC treatment and started the DAA therapy between August 2015 and December 2016 were enrolled. Chronic hepatitis $\mathrm{C}$ was defined as the presence of the anti-HCV antibody and HCV RNA for more than 6 months. HCC was diagnosed if the tumor had a minimum diameter $\geq 1$ $\mathrm{cm}$, and if typical features of HCC (arterial phase hyperenhancement, washout in the portal venous or delayed phase, threshold growth, and capsule appearance) were observed using multiphase computed tomography and/or magnetic resonance imaging. If these criteria were present but there was a lack of a diagnostic certainty, a liver biopsy was performed to confirm the diagnosis of HCC. ${ }^{19}$ Patients were excluded if they met any of the following criteria: evidence of autoimmune hepatitis or viral co-infection, such as those with the hepatitis B virus or the human immunodeficiency virus; alcohol consumption $>210 \mathrm{~g}$ per week for males and >140 g per week for females; no CR after HCC treatment prior to DAA therapy; liver transplantation before DAA therapy; no tumor status assessment after starting DAA therapy; and/or treatment with interferon as part of DAA therapy. The patients were followed-up until HCC recurrence or until January 2018.

For external validation, we used data from patients with an HCV-infected HCC from the Korean Health Insurance Review and Assessment Service (HIRA) ${ }^{20}$ (Supplementary Fig. 1). HIRA data, which is generated in the process of reimbursing healthcare providers under National Health Insurance, contains specific, yet comprehensive information on the relevant healthcare services, such as procedures, surgeries, examinations, and treatment, including prescriptions and socio-demographic characteristics of patients. In South Korea, National Health Insurance covers approximately $98 \%$ of the total population. Moreover, all healthcare providers are required to be covered under the National Health Insurance, which is based on feefor-services. ${ }^{20}$ Subjects with HCC (C220 and C229) who were prescribed DAA therapy (638101ATB [daclatasvir], 638001ACH [asunaprevir], 644401ATB [sofosbuvir], 645800ATB [ledipasvir/sofosbuvir], 223604ACH, $223601 \mathrm{ACH}$, and 223601 ACH [ribavirin]) between August 2015 and December 2016 were extracted from the HIRA database using the International Classification of Diseases (10th edition) ${ }^{21,22}$ The exclusion criteria were as follows: autoimmune hepatitis (K75.4) or viral co-infection, including those with the hepatitis B (B18.0, B18.10, B18.18, B18.1, and Z22.5) and the human immunodeficiency virus (Z21.X, Z86.X, B20.X, B21.X, B22.X, B23.X, and B24.X); liver transplantation before DAA therapy; history of DAA therapy before or during HCC treatment. HCC recurrence was defined as reinitiation of HCC treatment after DAA therapy. The patients were followed-up until HCC recurrence or until December 2016. The study protocol was approved by the Institutional Review Board of the Ajou University Hospital (IRB number: AJIRB-MEDMDB-17-031).

\section{Definitions}

Baseline characteristics, including age, liver function, and the HCV RNA level, were documented at the start of the DAA therapy. HCC treatment duration was defined as the time between the initial HCC treatment and the last HCC treatment before a DAA therapy. Last HCC treatment durability was defined as the time between the final HCC treatment and the start of a DAA therapy. HCC recurrence time was calculated from the start of a DAA treatment. The SVR was determined 12 weeks after the end of a DAA treatment (SVR12). CR acquisition was defined according to modified RECIST criteria, disappearance of 
any intratumoral arterial enhancement in all target lesions on follow-up image study. ${ }^{23}$

\section{Statistics}

Data management and analysis were performed using the $\mathrm{R}$ statistical software (version 3.3.4; R Core Team [2014]; R: A language and environment for statistical computing; R Foundation for Statistical Computing, Vienna Austria; http://www.R-project.org/). Differences with $\mathrm{p}<0.05$ were considered statistically significant. All statistical analyses were performed using two-tailed tests: continuous variables were analyzed using the independent samples t-test while categorical data were compared using the Pearson chi-square test or the Fisher exact test. Cumulative probabilities of HCC recurrence were assessed by the Kaplan-Meier analysis. The Cox proportional hazard model was used to identify factors associated with HCC recurrence.

\section{RESULTS}

\section{Baseline characteristics of the multicenter cohort}

The mean age of the subjects was $69.2 \pm 8.4$ years, and $67 \%$ of them were male. The patients were the most commonly infected with the HCV genotype $1 \mathrm{~b}(66 \%)$, followed by the genotype $2(32 \%)$, genotype $1 \mathrm{a}(1 \%)$, and genotype $4(1 \%)$. Cirrhosis and diabetes mellitus were diagnosed in $79 \%$ and $33 \%$ of the patients, respectively. HCC in BCLC (Barcelona Clinic Liver Cancer) stages B or C was detected in $11 \%$ of the cohort, whereas modified Union for International Cancer Control stage III or IV disease was found in $12 \%$ of the patients; $23 \%$ of the subjects had previously received an interferon based therapy (Table 1).

Among the 100 subjects with an HCV-related HCC, 24 underwent radiofrequency ablation (RFA) therapy, 21 were treated with a transarterial chemoembolization (TACE), 19 experienced liver resection, two underwent radiation therapy, one received a transarterial radioembolization, and 33 were treated with multimodal therapy. Regarding the modality of the last HCC treatment, TACE (36\%) was the most frequently used, followed by RFA (33\%), liver resection $(21 \%)$, combination therapy $(6 \%)$, and other therapies (4\%). The median follow-up period after a DAA treatment start was 15.8 months (range, 4.4 to 29.9 months).

\section{Efficacy of DAA therapy in patients with HCC}

The efficacy of DAA therapy in patients with HCC is summarized in Fig. 1. Among the 100 patients in the multicenter cohort, 88 achieved SVR12 with DAA therapy. Even in those who experienced HCC recurrence, the
Table 1. Baseline Characteristics of 100 Multicenter Cohort Subjects

\begin{tabular}{|c|c|}
\hline Characteristics & Value $(n=100)$ \\
\hline Age, yr & $69.2 \pm 8.4$ \\
\hline Male sex & $67(67)$ \\
\hline Diabetes mellitus & 33 (33) \\
\hline Liver cirrhosis & $79(79)$ \\
\hline \multicolumn{2}{|l|}{ Child-Pugh } \\
\hline A & 95 (95) \\
\hline $\mathrm{B}$ & $4(4)$ \\
\hline C & $1(1)$ \\
\hline \multicolumn{2}{|l|}{ BCLC stage } \\
\hline 0 & $34(34)$ \\
\hline A & $55(55)$ \\
\hline B & $7(7)$ \\
\hline C & $4(4)$ \\
\hline \multicolumn{2}{|l|}{ mUICC stage } \\
\hline I & $48(48)$ \\
\hline ॥ & $40(40)$ \\
\hline III & $10(10)$ \\
\hline IV & $2(2)$ \\
\hline Hemoglobin, g/dL & $13.0 \pm 1.5$ \\
\hline Platelet, $\times 10^{3} / \mu \mathrm{L}$ & $112.1 \pm 57.5$ \\
\hline Creatinine, $\mathrm{mg} / \mathrm{dL}$ & $0.80 \pm 0.19$ \\
\hline Albumin, g/dL & $3.67 \pm 0.47$ \\
\hline Total bilirubin, $\mathrm{mg} / \mathrm{dL}$ & $1.08 \pm 0.55$ \\
\hline AST, IU/L & $63.7 \pm 33.0$ \\
\hline ALT, IU/L & $46.5 \pm 30.6$ \\
\hline INR & $1.08 \pm 0.18$ \\
\hline AFP, ng/mL & $37.7 \pm 75.1$ \\
\hline \multicolumn{2}{|l|}{ HCV genotype } \\
\hline $1 a$ & $1(1)$ \\
\hline $1 b$ & $66(66)$ \\
\hline 2 & 32 (32) \\
\hline 4 & $1(1)$ \\
\hline Previous interferon-based treatment & $23(23)$ \\
\hline HCV RNA, $\log _{10} I U / m L$ & $5.42 \pm 0.92$ \\
\hline \multicolumn{2}{|l|}{ DAA combination } \\
\hline Daclatasvir+asunaprevir & $59(59)$ \\
\hline Sofosbuvir+ribavirin & 33 (33) \\
\hline Ledipasvir/sofosbuvir & $8(8)$ \\
\hline
\end{tabular}

Data are presented as the mean \pm SD or number (\%).

BCLC, Barcelona Clinic Liver Cancer; mUICC, modified Union for International Cancer Control; AST, aspartate aminotransferase; ALT, alanine aminotransferase; INR, international normalized ratio; AFP, alpha-fetoprotein; $\mathrm{HCV}$, hepatitis $\mathrm{C}$ virus; DAA, direct-acting antiviral agent.

SVR12 acquisition rate was as high as $86.5 \%(32 / 37)$. SVR12 was achieved by $86.1 \%(68 / 79)$ of patients with liver cirrhosis and by $95.2 \%(20 / 21)$ of those without it. The SVR 12 rate was $87.9 \%$ (58/66) and $87.5 \%$ (28/32) with the genotypes $1 \mathrm{~b}$ and 2 , respectively. The only patient with genotype $1 \mathrm{a}$ and the only patient with genotype 4 acquired SVR12. Of the 36 patients who started the DAA therapy within 6 months of the last HCC treatment, 33 (91.7\%) obtained SVR12. The SVR12 rate did not significantly differ between the groups (Fig. 1). 


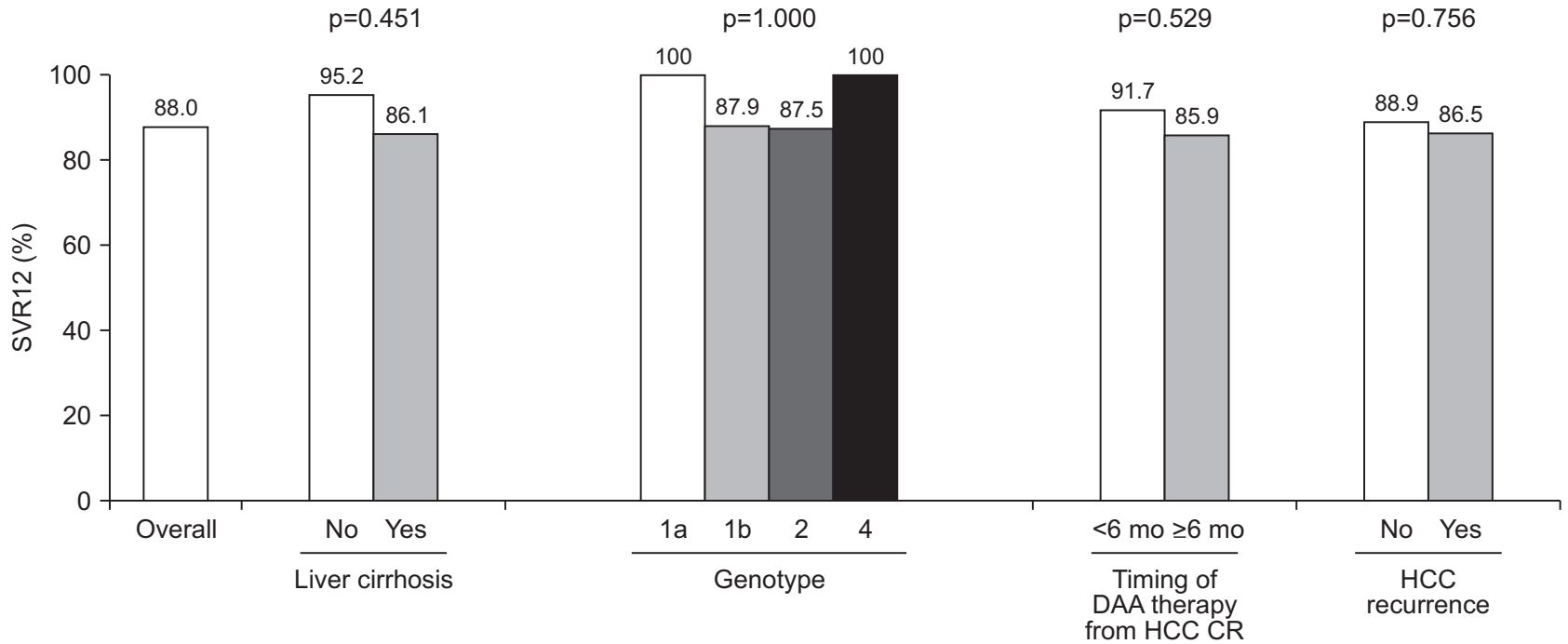

Fig. 1. Rates of the SVR 12 weeks after the end of DAA therapy (SVR12) in patients with hepatitis C virus-related HCC.

SVR, sustained virological response; DAA, direct-acting antiviral agent; $\mathrm{HCC}$, hepatocellular carcinoma; CR, complete response.

\section{Details of $\mathbf{3 7}$ patients with HCC recurrence after DAA therapy}

During the median follow-up period of 15.8 months (range, 4.4 to 29.9 months), $37 \%$ of the study subjects experienced HCC recurrence; the 1-year and 2-year cumulative recurrence rate was $28.4 \%$ and $61.3 \%$, respectively. The median number and size of the recurrent tumors were 1 (range, 1 to 6) and $1.25 \mathrm{~cm}$ (range, 0.8 to $5.7 \mathrm{~cm}$ ), respectively. Regarding the pattern of recurrence, a new intrahepatic recurrence $(62.2 \%)$ was most commonly detected, followed by a marginal recurrence $(16.2 \%)$, and a marginal recurrence combined with a new intrahepatic recurrence (5.4\%). Extrahepatic recurrence was not observed. The majority of the patients $(67.6 \%)$ were treated with TACE, $16.2 \%$ underwent RFA, while $5.4 \%$ received RFA as well as TACE. Radiation therapy, TACE followed by radiation therapy, and TACE followed by sorafenib were used in 2.7\% of the cases each. After HCC recurrence, $58.8 \%$ of the patients showed CR while $14.7 \%$ obtained a partial response. Stable and progressive disease were observed in $5.9 \%$ and $20.6 \%$ of the cases, respectively.

\section{Risk factors for HCC recurrence in the multicenter cohort}

According to the univariate analysis, low platelet levels $(\mathrm{p}=0.040)$, HCC treatment with a noncurative method such as TACE, transarterial radioembolization, hepatic artery infusion chemotherapy, sorafenib and radiotherapy $(\mathrm{p}<0.001)$, last HCC treatment with a noncurative method $(\mathrm{p}<0.001)$, HCC treatment duration more than 18 months $(\mathrm{p}=0.009)$, and last HCC treatment durability less than 12 months ( $\mathrm{p}=0.006$ ) were related to HCC recurrence. In con- trast, age $(\mathrm{p}=0.127)$, liver cirrhosis ( $\mathrm{p}=0.159)$, and SVR12 $(\mathrm{p}=0.934)$ were not associated with HCC recurrence (Table 2). Multivariate Cox regression analysis showed that short last HCC treatment durability ( $<12$ months) was only independently associated with HCC recurrence in patients with the HCV-related HCC after the DAA treatment (hazard ratio [HR], 2.89; 95\% confidence interval [CI], 1.27 to 6.59; $\mathrm{p}=0.011$ ) (Table 3, Fig. 2).

In subgroup analysis with patients who were treated with curative modality, mean HCC treatment durability $(\mathrm{p}=0.046)$ and last HCC treatment durability less than 12 months ( $\mathrm{p}=0.036$ ) were related to HCC recurrence. In ageand sex-adjusted multivariate Cox regression analysis, the relationship between last HCC treatment durability and HCC recurrence showed no statistical significance $(\mathrm{p}=0.058)($ Supplementary Table 1$)$.

\section{External validation using the HIRA cohort}

A total of 526 patients with HCV-related HCC and treated with DAAs were identified in the HIRA cohort. Baseline characteristics of the validation cohort have been listed in Table 4. The mean age of the subjects was $66.9 \pm 9.6$ years, and $63.7 \%$ of them were male. Cirrhosis and diabetes were diagnosed in $87.1 \%$ and $70.5 \%$ of the cases, respectively, and $8 \%$ of the subjects had received a previous interferon based therapy. Among the 526 patients, 107 (20.3\%) experienced HCC recurrence.

In the univariate analysis, HCC treatment with a noncurative method, the last HCC treatment with a noncurative method, a long duration of the HCC treatment $(\geq 18$ months), and short last HCC treatment durability before a DAA therapy ( $<12$ months) were related to HCC recur- 
Table 2. Univariate Analysis for Risk Factors for HCC Recurrence in the Multicenter Cohort

\begin{tabular}{|c|c|c|c|}
\hline Variable & $\begin{array}{l}\text { Subjects without } \\
\text { HCC recurrence }(n=63)\end{array}$ & $\begin{array}{l}\text { Subjects with } \\
\text { HCC recurrence }(n=37)\end{array}$ & $\mathrm{p}$-value \\
\hline Age, yr & $68.7 \pm 8.9$ & $69.9 \pm 7.4$ & 0.127 \\
\hline Male sex & $42(66.7)$ & $25(67.6)$ & 0.926 \\
\hline Diabetes mellitus & 22 (34.9) & $11(29.7)$ & 0.594 \\
\hline Liver cirrhosis & $47(74.6)$ & 32 (86.5) & 0.159 \\
\hline Child-Pugh & & & 0.377 \\
\hline$A$ & 60 (95.2) & 35 (94.6) & \\
\hline B & $3(4.8)$ & $1(2.7)$ & \\
\hline C & 0 & $1(2.7)$ & \\
\hline Hemoglobin, g/dL & $13.0 \pm 1.6$ & $12.9 \pm 1.3$ & 0.238 \\
\hline Platelet, $\times 10^{3} / \mu \mathrm{L}$ & $121.9 \pm 64.5$ & $95.4 \pm 38.1$ & $0.040^{+}$ \\
\hline Total bilirubin, mg/dL & $1.06 \pm 0.57$ & $1.11 \pm 0.53$ & 0.399 \\
\hline Albumin, g/dL & $3.7 \pm 0.5$ & $3.6 \pm 0.4$ & 0.208 \\
\hline AST, IU/L & $62.4 \pm 30.7$ & $66.0 \pm 37.0$ & 0.831 \\
\hline ALT, IU/L & $46.9 \pm 30.0$ & $45.9 \pm 32.7$ & 0.570 \\
\hline Creatinine, $\mathrm{mg} / \mathrm{dL}$ & $0.81 \pm 0.20$ & $0.77 \pm 0.15$ & 0.145 \\
\hline INR & $1.07 \pm 0.19$ & $1.10 \pm 0.18$ & 0.823 \\
\hline AFP, $n g / m L$ & $30.4 \pm 65.0$ & $50.1 \pm 90.0$ & 0.405 \\
\hline HCV RNA, $\log _{10} \mathrm{IU} / \mathrm{mL}$ & $5.42 \pm 0.99$ & $5.42 \pm 0.79$ & 0.091 \\
\hline Genotype & & & 0.348 \\
\hline $1 \mathrm{a}$ & $1(1.6)$ & 0 & \\
\hline $1 b$ & $44(69.8)$ & 22 (59.5) & \\
\hline 2 & $18(28.6)$ & 14 (37.8) & \\
\hline 4 & 0 & $1(2.7)$ & \\
\hline SVR 12 & 56 (88.9) & 32 (86.5) & 0.934 \\
\hline BCLC stage & & & 0.248 \\
\hline 0 & 23 (36.5) & $11(29.7)$ & \\
\hline$A$ & $35(55.6)$ & $20(54.1)$ & \\
\hline $\mathrm{B}$ & 2 (3.2) & $5(13.5)$ & \\
\hline $\mathrm{C}$ & $3(4.8)$ & $1(2.7)$ & \\
\hline mUICC stage & & & 0.064 \\
\hline 1 & $34(54.0)$ & 14 (37.8) & \\
\hline$\|$ & $24(38.1)$ & $16(43.2)$ & \\
\hline III & $3(4.8)$ & $7(18.9)$ & \\
\hline IV & 2 (3.2) & 0 & \\
\hline HCC treatment using noncurative modality* & $27(42.9)$ & $29(78.4)$ & $<0.001^{+}$ \\
\hline Last HCC treatment using noncurative modality* & 20 (31.7) & 26 (70.3) & $<0.001^{+}$ \\
\hline HCC treatment duration ( $\geq 18 \mathrm{mo})$ & $12(19.0)$ & $16(43.2)$ & $0.009^{+}$ \\
\hline Last HCC treatment durability (<12 mol) & $32(50.8)$ & $29(78.4)$ & $0.006^{+}$ \\
\hline Last HCC treatment durability, day & $528.7 \pm 661.9$ & $271.5 \pm 319.6$ & $0.009^{+}$ \\
\hline DAA combination & & & 0.417 \\
\hline Daclatasvir+asunaprevir & 39 (61.9) & $20(54.1)$ & \\
\hline Sofosbuvir+ribavirin & $18(28.6)$ & 15 (40.5) & \\
\hline Ledipasvir/sofosbuvir & $6(9.5)$ & $2(5.4)$ & \\
\hline
\end{tabular}

Data are presented as the mean \pm SD or number $(\%)$.

HCC, hepatocellular carcinoma; AST, aspartate aminotransferase; ALT, alanine aminotransferase; INR, international normalized ratio; AFP, alpha-fetoprotein; HCV, hepatitis C virus; SVR, sustained virologic response; BCLC, Barcelona Clinic Liver Cancer; mUICC, modified Union for International Cancer Control; DAA, direct-acting antiviral agent.

*Noncurative modality included transarterial chemoembolization, transarterial radioembolization, hepatic artery infusion chemotherapy, sorafenib and radiotherapy; ${ }^{\dagger}$ Statistically significant, $p<0.05$.

rence (Table 5). Moreover, the multivariate Cox regression analysis showed that the last HCC treatment with a noncurative method (HR, 3.73; 95\% CI, 1.87 to 7.43 ; $\mathrm{p}<0.001$ ), HCC treatment duration $\geq 18$ months (HR, 1.74; 95\% CI, 1.16 to $2.60 ; \mathrm{p}=0.006$ ), the last HCC treatment durability
$<12$ months (HR, 3.34; 95\% CI, 1.95 to 5.71; $\mathrm{p}<0.001$ ) were independently associated with HCC recurrence (Table 5, Fig. 3). 


\section{DISCUSSION}

In the present study, short last HCC treatment durability before a DAA therapy ( $<12$ months) was an independent predictor of HCC recurrence in both the multicenter cohort and the nationwide cohort from the Korean HIRA database. To the best of our knowledge, this is the first study to evaluate the risk factors for predicting HCC recurrence after the DAA therapy in Korean patients with HCVrelated HCC.

Short last HCC treatment durability ( $<12$ months) was the only common independent risk factor for HCC recurrence in the both multicenter cohort and nationwide HIRA cohort. The last HCC treatment with a noncurative method and a long total duration of the HCC treatment ( $\geq 18$ months) prior to the DAA therapy were independent risk factors in the HIRA cohort, but not in the multicenter cohort. This discrepancy may be explained by differences

Table 3. Multivariate Analysis for Risk Factors for HCC Recurrence in the Multicenter Cohort

\begin{tabular}{lccc}
\hline \multicolumn{1}{c}{ Multivariate analysis } & $\mathrm{HR}$ & $95 \% \mathrm{Cl}$ & $\mathrm{p}$-value \\
\hline Platelet $\left(<10 \times 10^{3} / \mu \mathrm{L}\right)$ & 1.74 & $0.86-3.52$ & 0.119 \\
HCC treatment with noncurative modality* & 1.78 & $0.49-6.38$ & 0.374 \\
$\begin{array}{l}\text { Last HCC treatment with noncurative } \\
\quad \text { modality* }\end{array}$ & 2.18 & $0.69-6.82$ & 0.179 \\
HCC treatment duration $(\geq 18 \mathrm{mo})$ & 1.97 & $0.99-3.88$ & 0.050 \\
Last HCC treatment durability $(<12 \mathrm{mo})$ & 2.89 & $1.27-6.59$ & $0.011^{\dagger}$ \\
\hline
\end{tabular}

$\mathrm{HCC}$, hepatocellular carcinoma; $\mathrm{HR}$, hazard ratio; $\mathrm{Cl}$, confidence interval.

*Noncurative modality included transarterial chemoembolization, transarterial radioembolization, hepatic artery infusion chemotherapy, sorafenib and radiotherapy; ${ }^{\dagger}$ Statistically significant, $p<0.05$.

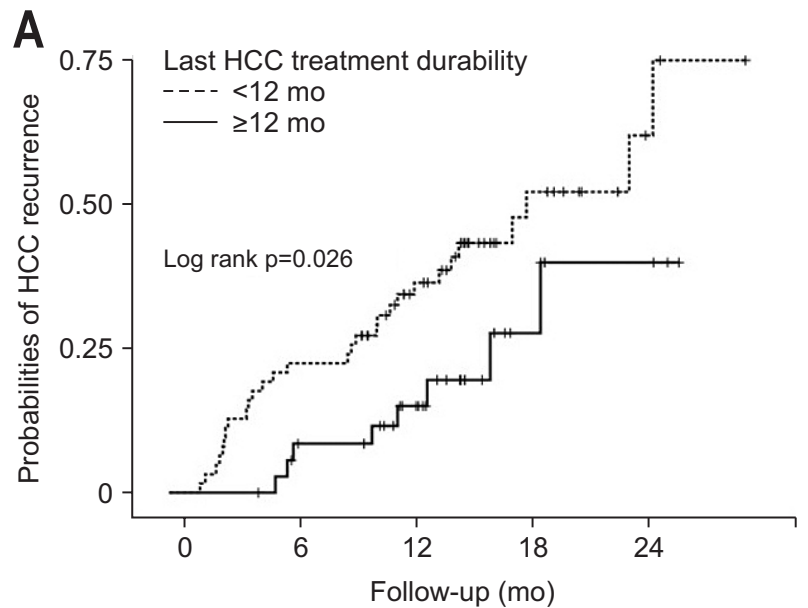

No. at risk

$\begin{array}{rrrrrr}--- & 63 & 49 & 33 & 11 & 2 \\ - & 37 & 33 & 23 & 6 & 2\end{array}$

in the two study populations. HIRA data, as national claims data, does not include information on the HCC stage or radiological findings, making it difficult to confirm CR in patients. Therefore, the validation cohort was more heterogeneous than the test cohort, which may have contributed to different risk factors for HCC recurrence in the two study groups.

Table 4. Baseline Characteristics of 526 Subjects in the HIRA Cohort

\begin{tabular}{lc}
\hline \multicolumn{1}{c}{ Characteristics } & Value $(\mathrm{n}=526)$ \\
\hline Age, yr & $66.9 \pm 9.6$ \\
Male sex & $335(63.7)$ \\
Diabetes mellitus & $371(70.5)$ \\
Liver cirrhosis & $458(87.1)$ \\
Previous interferon-based treatment & $42(8.0)$ \\
DAA combination & \\
Daclatasvir+asunaprevir & $327(62.2)$ \\
Sofosbuvir+ribavirin & $127(24.1)$ \\
Ledipasvir/sofosbuvir & $61(11.6)$ \\
Sofosbuvir+daclatasvir & $11(2.1)$ \\
HCC treatment modality before DAA therapy & \\
Resection & $3(0.6)$ \\
RFA & $135(25.7)$ \\
TACE & $226(43.0)$ \\
Multi-modality & $146(27.8)$ \\
Other therapies & $16(2.9)$ \\
Last HCC treatment modality before DAA therapy & \\
Resection & $4(0.8)$ \\
RFA & $185(35.2)$ \\
TACE & $296(56.3)$ \\
Combination treatment & $17(3.2)$ \\
Other therapies & $24(4.6)$ \\
\hline
\end{tabular}

Data are presented as the mean \pm SD or number (\%).

HIRA, Health Insurance Review and Assessment; DAA, direct-acting antiviral agent; HCC, hepatocellular carcinoma; RFA, radiofrequency ablation; TACE, transarterial chemoembolization.

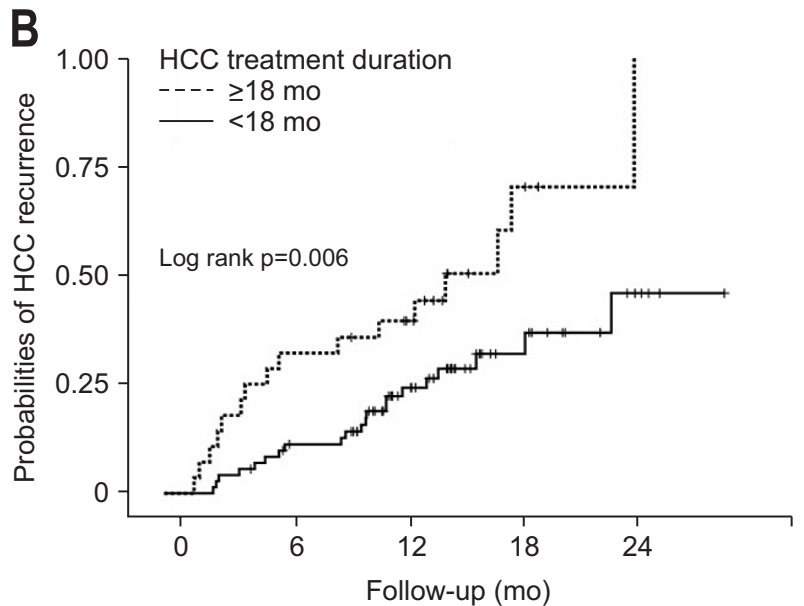

No. at risk

$\begin{array}{llllll}-- & 72 & 63 & 40 & 14 & 4 \\ - & 28 & 28 & 19 & 16 & 3\end{array}$

Fig. 2. Cumulative probabilities of a recurrence of hepatocellular carcinoma ( $\mathrm{HCC}$ ) according to the last $\mathrm{HCC}$ treatment durability (A) and the total duration of the HCC treatment (B) in the multicenter cohort. 
Table 5. Risk Factor Analysis for HCC Recurrence in the HIRA Cohort

\begin{tabular}{|c|c|c|c|c|c|c|}
\hline \multirow{2}{*}{ Risk factor } & \multirow{2}{*}{$\begin{array}{c}\text { Subjects without } \\
\text { HCC recurrence } \\
\text { (n=419) }\end{array}$} & \multirow{2}{*}{$\begin{array}{c}\text { Subjects with } \\
\text { HCC recurrence } \\
\text { (n=107) }\end{array}$} & \multirow{2}{*}{$\begin{array}{l}\text { Univariate } \\
\text { p-value }\end{array}$} & \multicolumn{3}{|c|}{ Multivariate analysis } \\
\hline & & & & $\mathrm{HR}$ & $95 \% \mathrm{Cl}$ & p-value \\
\hline Age, yr & $66.8 \pm 9.8$ & $67.4 \pm 8.9$ & 0.867 & & & \\
\hline Male sex & $267(63.7)$ & $68(63.6)$ & 0.903 & & & \\
\hline Diabetes mellitus & $200(71.6)$ & $71(66.4)$ & 0.160 & & & \\
\hline Liver cirrhosis & 360 (85.9) & $98(91.6)$ & 0.103 & & & \\
\hline HCC treatment using noncurative modality* & $290(69.2)$ & 96 (89.7) & $<0.001^{+}$ & 0.75 & $0.42-1.33$ & 0.330 \\
\hline Last HCC treatment using noncurative modality* & $244(58.2)$ & 93 (86.9) & $<0.001^{+}$ & 3.73 & $1.87-7.43$ & $<0.001^{\dagger}$ \\
\hline HCC treatment duration $(\geq 18 \mathrm{mo})$ & $100(23.9)$ & $44(41.1)$ & $<0.001^{\dagger}$ & 1.74 & $1.16-2.60$ & $0.006^{+}$ \\
\hline Last HCC treatment durability ( $<12 \mathrm{mo})$ & $236(56.3)$ & 91 (85.0) & $<0.001^{+}$ & 3.34 & $1.95-5.71$ & $<0.001^{\dagger}$ \\
\hline
\end{tabular}

Data are presented as the mean \pm SD or number (\%).

$\mathrm{HCC}$, hepatocellular carcinoma; HIRA, Health Insurance Review and Assessment; HR, hazard ratio; $\mathrm{Cl}$, confidence interval.

*Noncurative modality included transarterial chemoembolization, transarterial radioembolization, hepatic artery infusion chemotherapy, sorafenib and radiotherapy; ${ }^{\dagger}$ Statistically significant, $\mathrm{p}<0.05$.

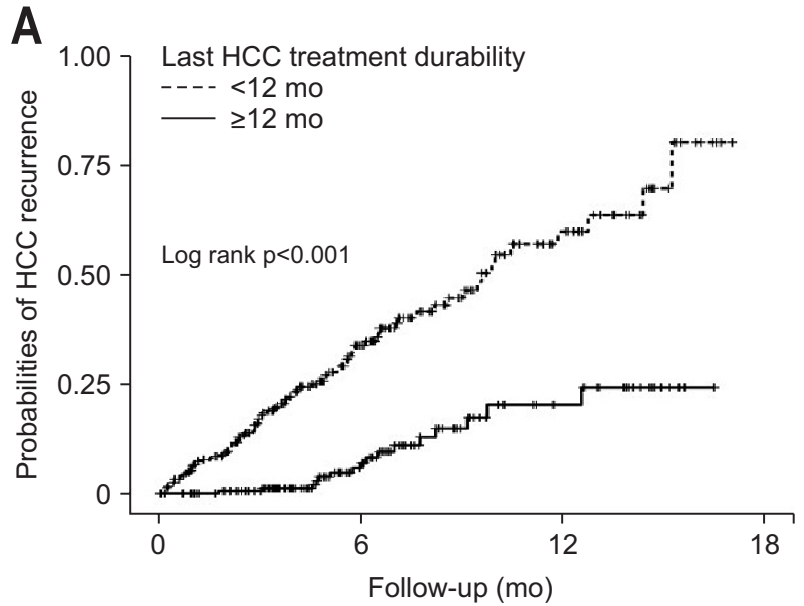

No. at risk

$$
\begin{array}{rr}
- & 199 \\
--- & 327
\end{array}
$$

$\begin{array}{rrr}88 & 26 & 0 \\ 114 & 34 & 0\end{array}$

0

Fig. 3. Cumulative probabilities of a recurrence of hepatocellular carcinoma ( $\mathrm{HCC}$ ) according to the last $\mathrm{HCC}$ treatment durability (A) and the total duration of the HCC treatment (B) in the nationwide Health Insurance Review and Assessment Service cohort.

Meanwhile, even if short last HCC treatment durability is an independent risk factor for HCC recurrence, it is difficult to interpret the finding that the delayed DAA therapy reduces the risk of HCC recurrence. Two recent meta-analyses and a large cohort study found that DAA therapy was not associated with an increased risk of HCC recurrence..$^{18,24,25}$ One of the meta-analyses pointed out that factors associated with HCC recurrence included a history of prior HCC recurrence and a short interval between HCC CR and initiation of the DAA treatment. The authors concluded that HCC recurrence rate was acceptable after the DAA therapy, particularly if the latter was delayed at least 6 months after HCC CR. ${ }^{24}$ However, a recent large cohort study that defined HCC recurrence time based on the timing of HCC CR showed that commencement of DAA therapy within 6 months of CR was not a risk factor

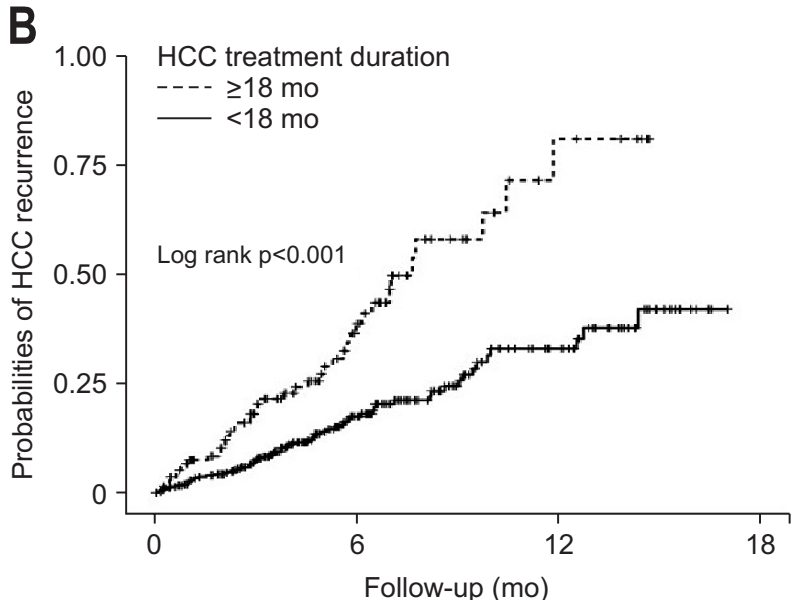

No. at risk

$\begin{array}{rrrrr}--- & 382 & 156 & 50 & 0 \\ --144 & 46 & 10 & 0\end{array}$

0 
a study with 59 patients who underwent a DAA therapy after HCC treatment who showed no significant differences in these factors between patients with and without HCC recurrence. ${ }^{15}$ While liver cirrhosis, diabetes mellitus, male gender, and old age are well-established risk factors for HCC development in patients with chronic hepatitis C, their role in HCC recurrence is unclear. This may be due to the differences in follow-up period between patients with a new and a recurrent HCC.

A few studies have suggested that patients with HCC are resistant to the DAA therapy. ${ }^{12-14}$ In 2017, Beste et al. ${ }^{13}$ reported that, of the 17,487 recipients of an HCV treatment, the overall SVR12 rate was $91.1 \%$ in the non-HCC group and $74.4 \%$ in the HCC group. In another study, the SVR12 rate was $79 \%$ and $88 \%$ in patients with and without HCC, respectively. ${ }^{14}$ There are several proposed theories explaining the observation of relatively low SVR12 rates in patients with HCC. HCC may act as a reservoir for HCV replication. ${ }^{12,30}$ Moreover, the HCC cells, which are mainly supplied by branches of the hepatic artery, ${ }^{31}$ and exhibit downregulated levels of the membrane transporters essential for the DAA uptake, such as OATP1B1, ${ }^{12,32}$ may have limited penetration of DAAs. Herein, the overall SVR12 rate after DAA therapy was $88 \%$, which increased to $91.7 \%$ in patients who underwent the DAA therapy within 6 months of the last HCC treatment. Considering the kind of DAA therapy in the current study (Table 1), an overall SVR12 rate of $88 \%$ is satisfactory. Further studies with more potent DAAs will be needed to confirm the efficacy of DAA therapy in patients with HCC.

The current study has several limitations. First, it did not include a control group, which made it difficult to ascertain whether DAA therapy itself could increase the risk of HCC recurrence. Second, this study included 46 patients who had received noncurative modality as last treatment. To secure as many patients as possible, patients with noncurative modality were also included. Considering this limitation, a subgroup analysis was conducted on 54 patients treated with curative method. Subgroup analysis showed that last HCC treatment durability less than 12 months was not significantly associated with HCC recurrence but tended to increase risk ( $\mathrm{p}=0.058)$. Further, we did not define the HCC recurrence time based on the timing of CR. The purpose of the current study was to define risk factors for HCC recurrence after the DAA therapy; thus, we started the follow-up after commencement of the DAA therapy. Additionally, patients treated with heterogenous methods were recruited, and it was not possible to confirm CR in the HIRA cohort. As very few patients with an HCV-related HCC have been treated with DAAs in South Korea, we sought to recruit as many participants as possible. We included patients who obtained a CR in the multicenter cohort, and confirmed the risk factors in the HIRA cohort, although the two cohorts partly overlapped.

In conclusion, the efficacy of DAA therapy was found to be acceptable in patients with an HCV-related HCC. However, short last HCC treatment durability before the DAA therapy ( $<12$ months) was associated with HCC recurrence. This finding suggests that the last HCC treatment response durability is an important predictor of HCC recurrence.

\section{CONFLICTS OF INTEREST}

No potential conflict of interest relevant to this article was reported.

\section{ACKNOWLEDGEMENTS}

This study was supported in part by the Scientific Research Fund of the Korean Liver Cancer Study Group (2017) and by a grant of the Korean Health Technology R\&D Project through the Korea Health Industry Development Institute, funded by the Ministry of Health \& Welfare, Republic of Korea (grant number: HI19C0872 and HI18C0531).

\section{AUTHOR CONTRIBUTIONS}

Study concept and design: S.S.K., J.Y.C. Data acquisition: H.L., D.Y.K., H.W.L., S.J.Y., Y.Y.C., J.W.J., B.K.J., C.W.K., H.Y.K., H.P. Data analysis and interpretation: Y.H.A., H.L., H.J.C., B.P. Drafting of the manuscript: Y.H.A., S.S.K. Critical revision of the manuscript for important intellectual content: S.S.K., J.Y.C. Statistical analysis: H.L., S.S.K. Obtained funding: S.S.K., J.Y.C. All authors approved the final draft of the manuscript submitted to the journal.

\section{ORCID}

Young-Hwan Ahn https://orcid.org/0000-0001-9920-1846 Heirim Lee

Do Young Kim https://orcid.org/0000-0002-1941-2238

Hye Won Lee

Su Jong Yu

Young Youn Cho Jeong Won Jang https://orcid.org/0000-0002-8327-3439 https://orcid.org/0000-0002-1626-6423 https://orcid.org/0000-0001-8888-7977 https://orcid.org/0000-0002-9384-5357 Byoung Kuk Jang https://orcid org/0000-0002-8950-0866 
Chang Wook Kim https://orcid.org/0000-0003-1184-0358

Hee Yeon Kim https://orcid.org/0000-0001-9669-5705

Hana Park

Hyo Jung Cho

Bumhee Park https://orcid.org/0000-0002-3917-9939 https://orcid.org/0000-0003-4792-8335 https://orcid.org/0000-0002-5271-1571 Soon Sun Kim https://orcid.org/0000-0002-6862-1896 Jae Youn Cheong https://orcid.org/0000-0001-6246-1783

\section{REFERENCES}

1. El-Serag HB. Hepatocellular carcinoma: an epidemiologic view. J Clin Gastroenterol 2002;35(5 Suppl 2):S72-S78.

2. Bray F, Ferlay J, Soerjomataram I, Siegel RL, Torre LA, Jemal A. Global cancer statistics 2018: GLOBOCAN estimates of incidence and mortality worldwide for 36 cancers in 185 countries. CA Cancer J Clin 2018;68:394-424.

3. Zeuzem S, Ghalib R, Reddy KR, et al. Grazoprevir-elbasvir combination therapy for treatment-naive cirrhotic and noncirrhotic patients with chronic hepatitis $\mathrm{C}$ virus genotype 1, 4, or 6 infection: a randomized trial. Ann Intern Med 2015;163:1-13.

4. Kowdley KV, Sundaram V, Jeon CY, et al. Eight weeks of ledipasvir/sofosbuvir is effective for selected patients with genotype 1 hepatitis C virus infection. Hepatology 2017;65:10941103.

5. Pol S, Bourliere M, Lucier S, et al. Safety and efficacy of daclatasvir-sofosbuvir in HCV genotype 1-mono-infected patients. J Hepatol 2017;66:39-47.

6. Luetkemeyer AF, McDonald C, Ramgopal M, Noviello S, Bhore R, Ackerman P. 12 Weeks of daclatasvir in combination with sofosbuvir for HIV-HCV coinfection (ALLY-2 Study): efficacy and safety by HIV combination antiretroviral regimens. Clin Infect Dis 2016;62:1489-1496.

7. Fried MW, Hadziyannis SJ. Treatment of chronic hepatitis C infection with peginterferons plus ribavirin. Semin Liver Dis 2004;24:47-54

8. Manns MP, McHutchison JG, Gordon SC, et al. Peginterferon alfa-2b plus ribavirin compared with interferon alfa- $2 b$ plus ribavirin for initial treatment of chronic hepatitis $\mathrm{C}$ : a randomised trial. Lancet 2001;358:958-965.

9. Lawitz E, Makara M, Akarca US, et al. Efficacy and safety of ombitasvir, paritaprevir, and ritonavir in an open-label study of patients with genotype $1 \mathrm{~b}$ chronic hepatitis $\mathrm{C}$ virus infection with and without cirrhosis. Gastroenterology 2015;149:971-980.

10. Charlton M, Everson GT, Flamm SL, et al. Ledipasvir and sofosbuvir plus ribavirin for treatment of HCV infection in patients with advanced liver disease. Gastroenterology 2015;149:649-659.

11. World Health Organization (WHO). Hepatitis C [Internet].
Geneva: WHO; c2020 [cited 2020 Jul 28]. Available from: https://www.who.int/en/news-room/fact-sheets/detail/ hepatitis-c.

12. Soria A, Fabbiani M, Lapadula G, Gori A. Unexpected viral relapses in hepatitis $\mathrm{C}$ virus-infected patients diagnosed with hepatocellular carcinoma during treatment with directacting antivirals. Hepatology 2017;66:992-994.

13. Beste LA, Green PK, Berry K, Kogut MJ, Allison SK, Ioannou GN. Effectiveness of hepatitis $\mathrm{C}$ antiviral treatment in a USA cohort of veteran patients with hepatocellular carcinoma. J Hepatol 2017;67:32-39.

14. Prenner SB, VanWagner LB, Flamm SL, Salem R, Lewandowski RJ, Kulik L. Hepatocellular carcinoma decreases the chance of successful hepatitis $\mathrm{C}$ virus therapy with directacting antivirals. J Hepatol 2017;66:1173-1181.

15. Conti F, Buonfiglioli F, Scuteri A, et al. Early occurrence and recurrence of hepatocellular carcinoma in HCV-related cirrhosis treated with direct-acting antivirals. J Hepatol 2016;65:727-733.

16. Reig M, Mariño Z, Perelló C, et al. Unexpected high rate of early tumor recurrence in patients with HCV-related HCC undergoing interferon-free therapy. J Hepatol 2016;65:719726.

17. Yang JD, Aqel BA, Pungpapong S, Gores GJ, Roberts LR, Leise MD. Direct acting antiviral therapy and tumor recurrence after liver transplantation for hepatitis C-associated hepatocellular carcinoma. J Hepatol 2016;65:859-860.

18. Waziry R, Hajarizadeh B, Grebely J, et al. Hepatocellular carcinoma risk following direct-acting antiviral HCV therapy: a systematic review, meta-analyses, and meta-regression. J Hepatol 2017;67:1204-1212.

19. Marrero JA, Kulik LM, Sirlin CB, et al. Diagnosis, staging, and management of hepatocellular carcinoma: 2018 practice guidance by the American Association for the Study of Liver Diseases. Hepatology 2018;68:723-750.

20. Kim JA, Yoon S, Kim LY, Kim DS. Towards actualizing the value potential of Korea Health Insurance Review and Assessment (HIRA) data as a resource for health research: strengths, limitations, applications, and strategies for optimal use of HIRA data. J Korean Med Sci 2017;32:718-728.

21. Abergel A, Rotily M, Branchoux S, et al. Chronic hepatitis C: burden of disease and cost associated with hospitalisations in France in 2012 (The HEPC-LONE study). Clin Res Hepatol Gastroenterol 2016;40:340-348.

22. Ford MM, Desai PS, Maduro G, Laraque F. Neighborhood inequalities in hepatitis $\mathrm{C}$ mortality: spatial and temporal patterns and associated factors. J Urban Health 2017;94:746755.

23. Lencioni R, Llovet JM. Modified RECIST (mRECIST) assessment for hepatocellular carcinoma. Semin Liver Dis 2010;30:52-60. 
24. Saraiya N, Yopp AC, Rich NE, Odewole M, Parikh ND, Singal AG. Systematic review with meta-analysis: recurrence of hepatocellular carcinoma following direct-acting antiviral therapy. Aliment Pharmacol Ther 2018;48:127-137.

25. Singal AG, Rich NE, Mehta N, et al. Direct-acting antiviral therapy not associated with recurrence of hepatocellular carcinoma in a multicenter North American cohort study. Gastroenterology 2019;156:1683-1692.

26. Chiba T, Matsuzaki Y, Abei M, et al. Multivariate analysis of risk factors for hepatocellular carcinoma in patients with hepatitis C virus-related liver cirrhosis. J Gastroenterol 1996;31:552-558.

27. Kanwal F, Kramer J, Asch SM, Chayanupatkul M, Cao Y, ElSerag HB. Risk of hepatocellular cancer in HCV patients treated with direct-acting antiviral agents. Gastroenterology 2017;153:996-1005.
28. Korean Association for the Study of the Liver (KASL). KASL clinical practice guidelines for management of chronic hepatitis B. Clin Mol Hepatol 2019;25:93-159.

29. European Association for the Study of the Liver. EASL clinical practice guidelines: management of hepatocellular carcinoma. J Hepatol 2018;69:182-236.

30. Prenner S, Kulik L. Reply to: "Treatment failure after interferon-free treatment of hepatitis $\mathrm{C}$ as a clue of a yet undetected hepatocellular carcinoma”. J Hepatol 2018;68:213-214.

31. Saberi B, Dadabhai AS, Durand CM, et al Challenges in treatment of hepatitis $\mathrm{C}$ among patients with hepatocellular carcinoma. Hepatology 2017;66:661-663.

32. Prenner SB, Kulik L. Hepatocellular carcinoma in the waitlisted patient with hepatitis $\mathrm{C}$ virus. Curr Opin Organ Transplant 2018;23:237-243. 